\title{
Microbiologia na revista Ciência Hoje das Crianças: análise de textos de divulgação científica
}

\section{The Microbiology in the Ciência Hoje das Crianças magazine: An analysis of scientific popularization texts}

Fernando Bueno Ferreira Fonseca de Fraga ${ }^{1}$.

Russel Teresinha Dutra da Rosa ${ }^{2}$

\begin{abstract}
Resumo: Este artigo investiga textos de divulgação científica (TDC), publicados na revista Ciência Hoje das Crianças, relacionados à microbiologia. As crianças, embora entrem em contato com microrganismos, não têm a oportunidade de observá-los diretamente, fator relevante na seleção dos textos para análise. O material foi analisado conforme as características do discurso de divulgação científica, descritas na literatura para textos voltados para adultos. Os resultados evidenciaram que esses elementos também ocorrem nos textos para o público infantil, corroborando a ideia de que a divulgação científica produz um discurso próprio, não se tratando de mera simplificação do científico. Os textos têm como marcas distintivas: o apelo à leitura feito mediante o uso de imagens, a informalidade da linguagem, e tentativas de aproximação do cotidiano das crianças, conforme pressupostas pelos autores dos artigos. Observou-se, também, que os textos versam de maneira atualizada e interdisciplinar sobre a microbiologia, oferecendo possibilidade de aplicação em aulas de ciências.
\end{abstract}

Palavras-chave: Divulgação científica. Ciência Hoje das Crianças. Revista. Microbiologia.

Abstract: This article aims to analyze scientific popularization texts related to microbiology published in the magazine "Ciência Hoje das Crianças". Children, in spite of their contact with microorganisms, do not observe them directly, a situation which is important regarding the selection of texts. The material was scrutinized in accordance with the characteristics of the discourse of scientific popularization, as described in the literature related to texts for adults. Results show that these features are also present in texts for children, which corroborates the idea that scientific popularization has a discourse of its own. The texts have, as their distinctive features, the appeal to reading done via the intervention of pictures and the use of informal language: an attempt to approach the children's daily lives, as presupposed by the authors of the texts. Also, they appeared to offer a interdisciplinary approach to microbiology, offering the possibility of the use the texts in science classes.

Key words: Scientific texts. Ciência Hoje das Crianças. Magazine. Microbiology.

\footnotetext{
1 Departamento de Fitossanidade, Faculdade de Agronomia, Universidade Federal do Rio Grande do Sul (UFRGS), Av. Bento Gonçalves, 7712, Agronomia, CEP 91540-000, Porto Alegre, RS, Brasil. E-mail: $<$ fernandocfh@yahoo.com.br>

${ }^{2}$ Departamento de Ensino e Currículo, Faculdade de Educação, Universidade Federal do Rio Grande do Sul (UFRGS), Porto Alegre, RS, Brasil.
} 


\section{Introdução}

O conhecimento pode ser gerado em diversas esferas da sociedade, de maneira formal ou não, e ser valorizado de acordo com as transformações históricas pelas quais passam os grupos que o produzem e o reelaboram. As diferentes exigências e finalidades dos contextos de produção, transmissão e aquisição definem especificidades a esse conhecimento, dentre as quais se destacam as transformações e recriações do conhecimento científico na constituição dos saberes escolares e da divulgação científica.

Pode-se pensar o conhecimento escolar em ciências e biologia como uma reprodução simplificada do que é gerado pelas ciências de referência. Essa visão enganosa baseia-se em relações hierárquicas, as quais tendem a classificar a produção de conhecimentos na escola como inferior, resultado de um empobrecimento do conhecimento científico. Todavia, um saber passa por mudanças epistemológicas quando é deslocado do contexto da pesquisa científica para o contexto escolar ou para o contexto de divulgação. Astolfi e Develay (1991, p. 48) afirmam que esse processo modifica a natureza do saber "[...] na medida em que se encontram deslocadas as questões que ele permite resolver, bem como a rede relacional que mantém com os outros conceitos [...]", de modo que os conteúdos de ensino "[...] resultam de cruzamentos complexos entre uma lógica conceitual, um projeto de formação e exigências didáticas" (ASTOLFI; DEVELAY, 1991, p. 51).

Assim como o campo do ensino, a divulgação científica igualmente realiza transformações nos saberes de referência. Essa prática exige diversas mudanças discursivas e estéticas a fim de apresentar as informações a um público amplo. O texto de divulgação científica (TDC) caracteriza-se como a materialização de um discurso próprio que sobrepõe elementos do discurso científico, do discurso pedagógico e do discurso informal próprio do cotidiano (NASCIMENTO; REZENDE JÚNIOR, 2010; ZAMBONI, 2001).

Nesse sentido, esta pesquisa teve como objetivo analisar as características do TDC relacionadas à microbiologia da Revista Ciência Hoje das Crianças.

\section{Divulgação científica e popularização da Ciência}

A divulgação científica (DC) pode ser realizada por diferentes veículos e em ambientes variados, por exemplo: internet, televisão, rádio, jornais, revistas, no espaço escolar, nos museus, em espaços informais, entre outros. De modo geral, a DC pode ser caracterizada como uma atividade de difusão do conhecimento científico, dirigida para fora do seu contexto original de produção, necessitando de diversos recursos e intervenções na maneira de apresentação desse conhecimento, a fim de torná-lo interessante e compreensível ao seu público-alvo (o público em geral, as crianças etc.).

Segundo José Reis (2002, p. 76), um dos pioneiros nessa atividade no Brasil, a divulgação científica "É a veiculação em termos simples da Ciência como processo, dos princípios nela estabelecidos, das metodologias que emprega". O editor-chefe da revista Scientific American Brasil, a define como "[...] um esforço de inteligibilidade do mundo que se busca e, ao mesmo tempo, se compartilha com os demais” (CAPOZOLI, 2002, p. 121). Já Zamboni (2001), ci- 
tando a tese de Bueno ${ }^{3}$, afirma ser a difusão científica uma atividade que se apresenta sob duas modalidades: (1) a disseminação científica e (2) a divulgação científica. A primeira refere-se à difusão do conhecimento científico para especialistas, enquanto a segunda tomaria como foco a difusão do conhecimento científico para o grande público. Quanto à disseminação científica, são caracterizados dois níveis: (a) disseminação intrapares, que é a circulação de informações para pesquisadores e especialistas de uma mesma área ou de áreas conexas; e (b) disseminação extrapares, que se destina a especialistas situados fora da área do objeto de disseminação. Com relação à divulgação científica, nesse quadro conceitual, inclui-se o jornalismo científico, os livros didáticos, as aulas de ciências, os programas de televisão, entre outros.

É importante ressaltar que diferentes termos são utilizados para tratar das questões referentes à difusão do conhecimento científico, tais como vulgarização da ciência; popularização da ciência e divulgação científica e, sem dúvida, cada termo representa, baseado em sua etimologia, diferentes relações e representações (GERMANO; KULESZA, 2007). Todavia, no presente trabalho, achamos apropriada a utilização do termo divulgação científica para toda a atividade destinada à difusão dos conhecimentos científicos que estejam deslocados do seu ambiente original de produção e validação e que se destinam ao público não especializado. A escolha desse termo se dá também em virtude de o periódico analisado nesse trabalho, a revista Ciência Hoje das Crianças, estar constantemente referido como revista de divulgação científica pela Sociedade Brasileira para o Progresso da Ciência (SBPC).

\section{A Divulgação da Ciência e sua influência na cultura e na sociedade}

A divulgação científica se caracteriza não somente pelas intervenções na linguagem e ressignificações, mas, também, pelo desempenho de uma função social singular. A ciência se consolidou no cotidiano do cidadão e na organização da sociedade, ainda que muitos de nós, $a$ priori, não consigamos estabelecer a relação entre nossas ações diárias e as inovações tecnológicas baseadas em pesquisas científicas. Nas últimas décadas, a ciência se modificou e alterou a sociedade, segundo Sarmento et al. (2010, p. 26) “[...] essa transformação se deu graças a um processo de retroalimentação entre Ciência e tecnologia”. Nesse contexto, a DC aproxima as pessoas do entendimento desses processos. Da mesma forma, uma compreensão da prática científica, suas falhas, riscos e controvérsias (FREIRE; MASSARANI, 2012; QUEIROZ, FERREIRA, 2013), das relações de forças entre grupos de interesse e um posicionamento crítico frente às decisões que afetam a todos, faz parte de uma cultura científica necessária à participação democrática.

É possível pensar na divulgação como um processo formativo, inclusivo, e uma forma de partilha social do saber; ou, até mesmo, uma prestação de contas da comunidade científica para os cidadãos, mas ela, também, pode ser tomada como um produto ou mercadoria que, para ser comercializada, deve interessar ao público. Por isso, trata-se de uma atividade a ser exercida com cautela, pois, além de apresentar as explicações dos processos da ciência para a sociedade,

\footnotetext{
${ }^{3}$ BUENO, W. C. Jornalismo científico no Brasil: os compromissos de uma prática dependente. 1984. 364 f. Tese (Doutorado) - Escola de Comunicações e Artes, Universidade de São Paulo, São Paulo, 1984.
} 
deve capacitar o grande público para entender que a ciência não responde a todas as perguntas e não fornece verdades definitivas. Segundo Sarmento et al. (2010, p. 28),

Em nome da Ciência, os meios de comunicação, entre eles televisão, revistas, jornais, Internet etc., divulgam o conhecimento e elevam o imaginário dos ouvintes, que acabam por acreditar que ela é capaz de resolver todos os problemas da humanidade.

Quantas verdades em ciência foram por terra assim que surgiram explicações mais precisas sobre determinado tema? Para Ulisses Capozoli (2002, p. 127-128):

Mais que acertos, que eventualmente podem se revelar erros, os reconhecidos erros indicam que a ciência é uma criação humana. Uma visão idealista, no sentido pejorativo desse termo algo controvertido, propõe uma natureza supra-humana para a ciência, o que, certamente, é uma perigosa cilada para um divulgador.

Sobre a perspectiva da ciência como produto de um contexto histórico, das investigações humanas e da sua estreita relação com a cultura, Candotti (2002) afirma que seu caráter investigativo e inovador coloca os costumes culturais e o senso comum em xeque, a fim de romper com os paradigmas de uma época.

\section{A divulgação científica para crianças}

Embora tenha ocorrido uma expansão do campo de DC para o público infantil, ainda são poucos os veículos que se dedicam, exclusivamente, a falar de ciência para crianças. O que comumente ocorre é a circulação de encartes ou de cadernos que atendam essa demanda em veículos para adultos, como os jornais Folha de São Paulo e O Globo, os quais foram examinados por Freire e Massarani (2012).

Nesse sentido, a revista Ciência Hoje das Crianças (CHC) é um referencial na consolidação da divulgação científica para esse público no Brasil. Ela é iniciativa do Instituto Ciência Hoje (ICH), uma organização sem fins lucrativos, vinculada à SBPC. Desde 1982, a SBPC publica periodicamente a revista Ciência Hoje e, desde 1986, a CHC, além de manter projetos e parcerias que se dirigem exclusivamente às crianças.

Atualmente, são publicadas 11 edições por ano da Revista (os meses de janeiro e fevereiro são editados em conjunto) e, também, é mantido um portal na internet voltado para o público infantil. Esse periódico possui diversas seções, que apresentam artigos, passatempos, experimentos e jogos, incidindo sobre diversas áreas das Ciências Humanas e das Ciências Naturais, elaborados por cientistas vinculados a instituições de pesquisa e, também, por jornalistas. Em reconhecimento à sua qualidade e pioneirismo, a $\mathrm{CHC}$ foi homenageada com o prêmio José Reis de Divulgação Científica no ano de 1991.

Além do seu importante papel na divulgação científica, a revista tem sido reconhecida como material de qualidade no apoio ao Ensino de Ciências na Educação Básica, sendo, des- 
de 1991, distribuída pelo Ministério da Educação para mais de 60 mil escolas da rede pública nacional ${ }^{4}$.

\section{Percurso teórico-metodológico}

O conjunto de dados definidos para a análise é composto por 12 artigos, extraídos da revista de divulgação científica Ciência Hoje das Crianças, os quais foram redigidos por cientistas vinculados a institutos de pesquisa e, também, por professores de ciências. A seleção do material foi feita observando-se os seguintes critérios:

a) Seções "por que" e "você sabia", por estabelecerem relações entre ciência e cotidiano, interpelando o leitor mediante indagações, de forma desafiadora e atualizada, em textos curtos, dirigidos a um público que pode ter os interesses dispersos rapidamente (BLUM, 1981 apud FREIRE; MASSARANI, 2012, p. 102). As perguntas que designam essas duas seções também podem contribuir para desestabilizar conhecimentos prévios e preconceitos (ROCHA, 2012), além de incluírem o leitor no próprio texto (ZAMBONI, 2001).

b) Textos relacionados à temática "microbiologia", por propiciarem a articulação de aspectos como: saúde-doença, tecnologia, ambiente, indústria, entre outros. Além disso, considerando o público-alvo da revista, as crianças, as quais, embora tenham contato com microrganismos, não costumam ter oportunidade de observá-los diretamente em seu cotidiano, pela exigência de instrumentos de laboratório (EMMERT, 2008).

c) Período de publicação entre janeiro de 2005 e junho de 2014, abrangendo todas as publicações sobre microbiologia das seções referidas, as quais passaram a integrar a estrutura da revista de maneira regular a partir de 2005.

Os 12 textos selecionados de acordo com os critérios acima foram examinados por meio de uma abordagem qualitativa, baseada na análise de conteúdo, com a finalidade de se compreenderem as especificidades do TDC dirigido ao público infantil. A análise dos documentos selecionados foi realizada tomando-se como parâmetro o estudo de Zamboni (2001), o qual delimita elementos presentes em textos jornalísticos de divulgação científica, tais como: apelo inicial à leitura, recuperação de conhecimentos tácitos, presença de procedimentos explicativos, interlocução direta com o leitor e presença de narrativa. Incluímos ainda, na análise, outros elementos que costumam ser frequentes nos TDC, tais como: as analogias, que podem facilitar a compreensão de conceitos novos, na medida em que fazem relações com conceitos mais familiares aos leitores (SILVA; PIMENTEL; TERRAZZAN, 2011), bem como a contextualização do conhecimento, que relaciona o conhecimento científico a referências do cotidiano dos leitores (LOPES, 1999). Devido à presença da $\mathrm{CHC}$ em bibliotecas escolares, o que facilita a sua utilização por professores no ensino de ciências (QUEIROZ; FERREIRA, 2013), decidimos, também, investigar como a microbiologia está representada nos TDC e suas possíveis aplicações em sala de aula.

\footnotetext{
${ }^{4}$ Disponível em: <http://cienciahoje.uol.com.br/instituto-ch/publicacoes/revistas>. Acesso em: 09 out. 2014.
} 


\section{Resultados e discussão}

Abaixo são apresentadas as descrições das categorias de análise empregadas e os trechos selecionados da revista em que se enquadram cada uma delas, bem como a discussão com base na literatura.

\section{Apelo inicial à leitura}

Refere-se a elementos que atraem e prendem a atenção do leitor e que o predispõem a explorar a informação inicialmente apresentada; um exemplo é a forma de apresentação do texto na página: em colunas, em "boxes", com diferentes tamanhos de fonte etc.. Podem também estar relacionados à presença de imagens e ilustrações; e, até mesmo, à seção em que o texto ocupa em determinado periódico.

Zamboni (2001) descreve recursos utilizados em textos de jornalismo científico, fruto da intersecção entre o discurso científico e o jornalístico, entre os quais estão: a presença de uma manchete atrativa e a segmentação da informação para atrair leitores que buscam informações específicas e de leitura rápida. No que se refere ao apelo inicial à leitura, na revista Ciência Hoje das Crianças, os recursos dizem respeito ao título das seções e às imagens que têm sua análise e discussão apresentadas a seguir.

\section{Impacto do título}

As seções da revista analisadas denominam-se Por que e Você sabia, sendo que o título dos textos sempre inicia com uma dessas expressões acompanhada do tema a ser abordado no artigo. No Quadro 1 estão reproduzidos os títulos encontrados.

Apresentar títulos na forma de perguntas realizadas insistentemente pelas crianças aos adultos pode despertar a curiosidade do jovem e motivá-lo para que continue a leitura do texto a fim de descobrir as respostas ali contidas (FREIRE; MASSARANI, 2012). As perguntas são formas de interlocução direta com o leitor, com a intenção de aproximá-lo e, até mesmo, de incluí-lo discursivamente. Mas a pergunta também demarca a distância entre o que o leitor supostamente sabe e o que requer explicação (NASCIMENTO; REZENDE JÚNIOR, 2010; QUEIROZ; FERREIRA, 2013). Os títulos E, G, H, I, J e K (Quadro 1) abordam situações cotidianas sobre as quais a criança possivelmente tenha experiências, havendo a possibilidade de ser construída uma interlocução entre suas vivências e a explicação científica oferecida.

\section{Presença de imagens}

As ilustrações são importantes recursos de apelo inicial à leitura e também podem ancorar as explicações científicas, uma vez que o texto verbal pode ser complementado ou sintetizado por meio da linguagem imagética (BURAKGAZI; YILDIRIM, 2014; MARTINS; GOUVÊA; PICCININI, 2005).

As seções Você sabia e Por que fazem uso extensivo de imagens. Com exceção do texto C, todos os demais apresentaram desenhos na sua composição. Essas representações exibem certa padronização, são desenhos estilizados e bem-humorados, dando unidade às seções. Con- 
têm as linhas gerais do tema de maneira independente, uma vez que não apresentam legendas explicativas e não se constituem em esquemas sobre os conceitos apresentados no texto, por isso, nem sempre, contribuem para a compreensão das explicações científicas. Em geral, são desenhos coloridos e grandes, ocupando quase metade da página do artigo. As crianças costumam fazer uso de desenhos de forma lúdica, expressando suas visões de mundo e emoções por meio deles (STUDART, 2008). O TDC lança mão dessa forma expressiva para promover leituras paralelas ao conteúdo verbal dos artigos (BAREDES, 2008).

Quadro 1. Revista Ciência Hoje das Crianças: referências dos textos analisados, títulos e autores

\begin{tabular}{|c|l|c|}
\hline \multicolumn{2}{|c|}{ Revista Ciência Hoje das Crianças } \\
\hline Texto & \multicolumn{1}{|c|}{ Título } & Autor(es) \\
\hline A & Por que microrganismos são importantes para as plantas? & Siqueira; Macrae \\
\hline B & Por que algumas bactérias são aliadas da saúde? & Costa; Medeiros \\
\hline C & $\begin{array}{l}\text { Você sabia que a Floresta Amazônica não é responsável por } \\
\text { grande parte do oxigênio que respiramos? }\end{array}$ & Quesado \\
\hline D & Você sabia que existem bactérias que produzem plástico? & Abreu \\
\hline E & Você sabia que cheirinho de terra molhada é obra de bactérias? & Silva \\
\hline F & $\begin{array}{l}\text { Você sabia que alguns cogumelos se reproduzem de maneira } \\
\text { parecida com as plantas? }\end{array}$ \\
\hline G & Por que os alimentos mofam? & Micheletti Neto \\
\hline H & Por que devemos vacinar os animais? & Guimarães; Borges \\
\hline I & Por que temos de tomar banho? & Bonomo; Cunha \\
\hline J & Por que o bolo cresce no forno? & Silva \\
\hline K & Por que alimentos, cosméticos e medicamentos estragam? & Lima \\
\hline L & Por que alguns vírus são mutantes? & Roehe \\
\hline
\end{tabular}

* Os artigos estão alfabetados nas referências pelo sobrenome do primeiro autor.

Fonte: Elaborado pelos autores.

A presença de figuras humanas é uma característica desses textos, constando em nove dos 12 artigos analisados, possivelmente com a finalidade de estabelecer um vínculo entre o leitor e o texto. Além disso, os ilustradores recorrem ao antropomorfismo dos seres não huma- 
nos, o que também foi descrito por Silveira (2013) ao analisar a representação de animais em textos e ilustrações da revista. Nota-se, na ilustração do texto D, que bactérias são representadas sorrindo, com pernas e braços (Figura 1).

Figura 1. Ilustração presente no texto D

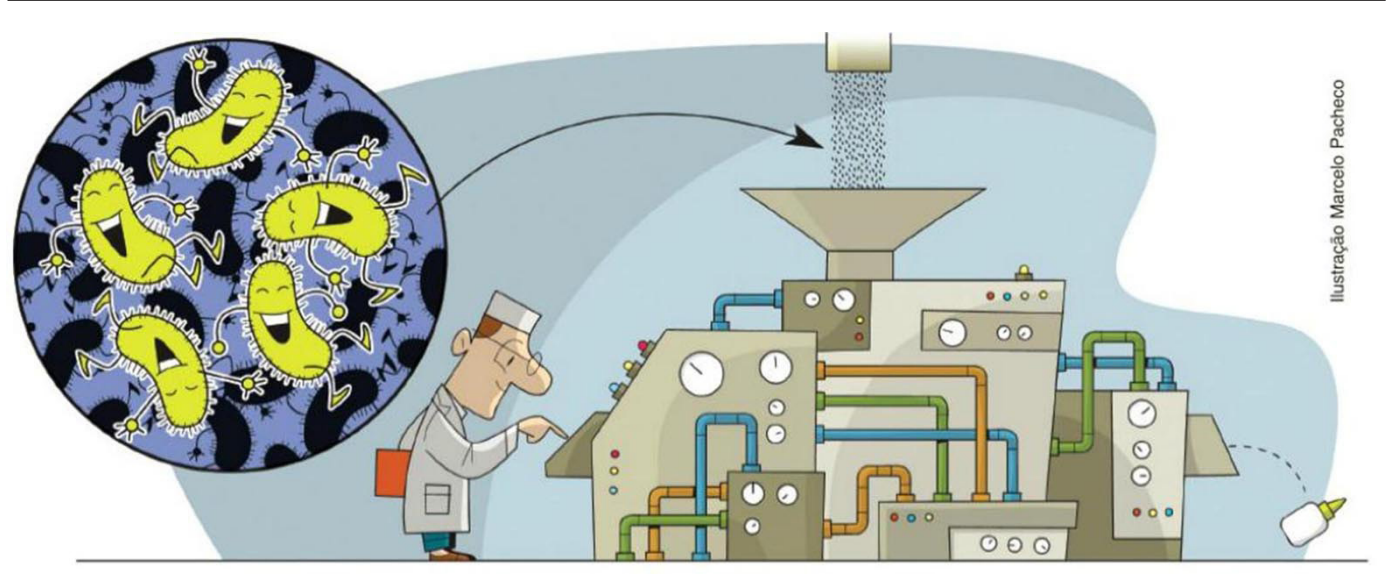

Fonte: Abreu (2009).

A fidelidade dos desenhos na DC é tema de discussões, uma vez que esse material cria representações dos seres vivos que podem ser divulgadas e se estabelecerem para os leitores de maneira errônea. Machado (2002, p. 145) considera que, no caso de animais mais conhecidos, como patos, cavalos, cães e coelhos, o ilustrador tem maior liberdade; “já quando o animal é menos conhecido, como bicho-pau ou macuco, o ilustrador não deve fugir muito da realidade, mas pode humanizar o animal fazendo-o expressar alegria, medo, curiosidade etc". Esse problema foi observado nos textos $\mathrm{D}$ (bactérias sorrindo e com pernas) e F (cogumelos com expressão antropomórfica).

No que diz respeito a desenhos esquemáticos que auxiliem na explicação, foi observado apenas um caso, no texto $\mathrm{F}$. Enquanto termos científicos que se referem às partes que compõem a estrutura de um cogumelo são explicados no texto escrito, é colocada, ao lado desse trecho, uma imagem explicativa (Figura 2).

Nas seções avaliadas, observamos, também, o uso de fotografias, que foi constatado em quatro textos. No texto A, que faz referência a bactérias fixadoras de nitrogênio associadas a raízes de plantas, é reproduzida uma fotografia que pretende mostrar essa associação. A fotografia (Figura 3) é apresentada apenas com o nome científico da bactéria referida no texto, e não há legenda ou referência, no corpo do documento, que explique os itens componentes da imagem. Sequer a informação de que se trata de uma fotografia de raiz aparece. Dentre as três fotografias localizadas nas seções Por que e Você sabia da CHC, duas não apresentavam legenda, e a terceira apresentava informações inacessíveis ao público leigo. 
Figura 2. Esquema presente no texto $\mathrm{F}$

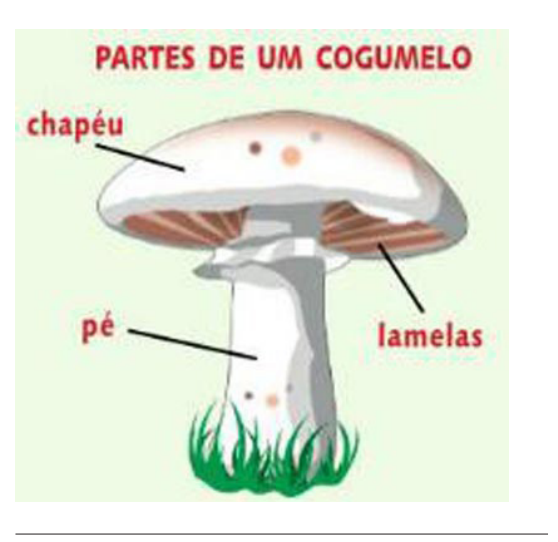

Fonte: Pereira (2009)

Figura 3. Fotografia presente no texto A

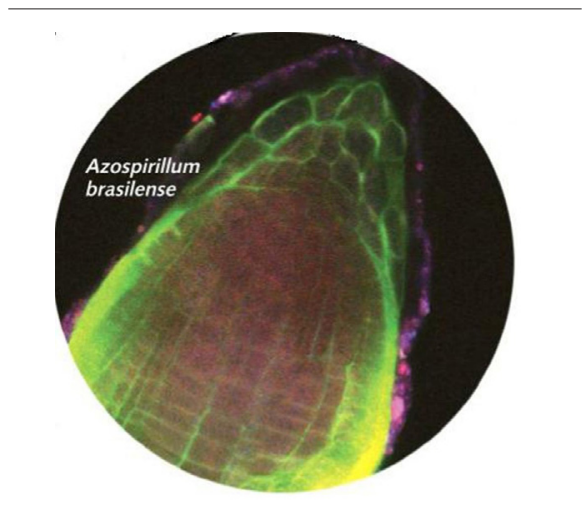

Fonte: Siqueira; Macrae (2012).

\section{Recuperação de conhecimentos tácitos}

Existem conhecimentos que não circulam no discurso científico, ainda que estejam implicados à temática, por serem tomados como conhecimentos tácitos e comuns a todos da área em questão ou, ainda, conhecimentos estabelecidos sobre os quais não cabe mais contestação (ZAMBONI, 2001).

Entretanto, quando o conhecimento está sendo apresentado para fins de divulgação, os pressupostos do autor com relação ao destinatário do texto se alteram. E, se o objetivo do texto é atingir uma quantidade maior de pessoas, os conhecimentos tácitos são retomados e passam a fazer parte, explicitamente, do discurso. A presença desses elementos indica, ainda, algumas possíveis representações acerca do leitor que figuram no imaginário do enunciador. Abaixo, estão destacados segmentos onde são retomados conhecimentos tácitos: 
Quando o assunto é bactéria, a maior parte das pessoas pensa logo em doenças. Alguns desses micro-organismos são mesmo os vilões da nossa saúde, podendo causar graves problemas. Mas muitas bactérias são aliadas da espécie humana, porque beneficiam o funcionamento do nosso organismo. [Texto B]

A importância das bactérias em processos não relacionados ao adoecimento já é amplamente difundida entre os cientistas, e não precisaria ser retomada caso o texto se dirigisse a eles.

Ué, e cogumelo não é planta? Não! De jeito nenhum! Os cogumelos não pertencem ao reino animal, tampouco ao vegetal. Eles são de um reino à parte, o reino fungi. [Texto $\mathrm{F}$ ]

Para o público leigo, o cogumelo pode não ser considerado vivo ou ser confundido com um vegetal, sendo necessária a apresentação de noções gerais de taxonomia.

Em todos os textos analisados, foi observada a recuperação de conhecimentos tácitos porque podem representar o primeiro contato que alguns leitores estabeleceram com os assuntos abordados; e, em outros casos, podem configurar-se como mudanças de perspectiva sobre situações do cotidiano, que passam a ser compreendidas a partir da ótica da ciência.

\section{Presença de procedimentos explicativos}

Referem-se a proposições curtas de natureza explicativa, as quais aparecem interrompendo o desenvolvimento das ideias centrais do texto, e têm por objetivo tornar claros os significados de termos técnico-científicos básicos. O enunciador assume que o discurso direciona-se a um receptor leigo, não familiarizado com termos científicos, exercendo uma ação didática de compartilhamento de saberes (ZAMBONI, 2001).

A presença de procedimentos explicativos foi um elemento recorrente nas duas seções analisadas da revista Ciência Hoje das Crianças. Dentre os textos analisados, apenas o texto $\mathrm{B}$ não apresentou esse recurso explicativo junto a termos científicos. Tal cuidado é necessário uma vez que a linguagem científica, embora pouco acessível aos alunos, precisa ser adquirida simultaneamente ao aprendizado em Ciências (BRAGA; MORTIMER, 2003). Abaixo, estão representados trechos com procedimentos explicativos:

Quanto menores são os organismos, mais rápido é o seu metabolismo, as reações químicas que ocorrem dentro do corpo. No caso dessas espécies, essas reações estão diretamente ligadas à fotossíntese, processo pelo qual, utilizando-se da luz do Sol, os vegetais produzem o seu próprio alimento e liberam oxigênio. [Texto C, grifos nossos]

Quando vacinamos nossos bichos de estimação... estamos nos protegendo das chamadas zoonoses, que são doenças que eles podem transmitir para o ser humano ou vice-versa, como a raiva e a leptospirose. [Texto $\mathrm{H}$, grifo nosso] 
Nos trechos destacados acima, nota-se que os autores recorrem ao uso de procedimentos explicativos, seja por meio de definições (exemplo: fotossíntese é o processo pelo qual, utilizando-se da luz do Sol, os vegetais produzem o seu próprio alimento), seja por meio de nomeações (ex.: doenças transmitidas por animais são chamadas de zoonoses). Ainda assim, alguns conceitos científicos podem permanecer incompreendidos para os jovens (AIRES et al., 2003; FREIRE; MASSARANI, 2012), os quais diminuem a transparência semântica, como: o significado da ideia de reações químicas, o conceito de espécie, o modo como ocorre a produção de alimentos pelas plantas, e o que é o oxigênio (no texto C). Por outro lado, o TDC informa e entretém, em um discurso híbrido, sem ser exaustivo, busca despertar o interesse e suscitar novas questões em um estilo informal (BAREDES, 2008; TOROK, 2008).

\section{Interlocução direta com o leitor}

Em todos os textos analisados, foi observada a intenção de simular um diálogo entre o autor e a audiência. É possível notar essa interlocução em perguntas diretas, sugestões, utilização de pronomes de tratamento que interpelam o leitor, a fim de buscar a sua participação ativa, mesmo que, para isso, seja necessário provocar uma "suspensão no desenvolvimento do texto" (ZAMBONI, 2001, p. 111). Abaixo, estão representados alguns trechos com perguntas diretas, as quais têm a finalidade de interagir com o destinatário e despertar a sua curiosidade:

Mas sabia que existem alimentos mofados que não estão estragados? Um exemplo é o queijo gorgonzola [...]. [Texto G]

O bolo, que a princípio era uma massa mole e disforme, cresceu e tomou forma dentro do forno. Uma metamorfose que não se deve a um milagre e, sim, à química. Quer ver só? [Texto J]

A inclusão do leitor no texto e a aproximação do mesmo com o conteúdo divulgado estão expressas, também, na utilização do pronome de tratamento "você". Esse recurso está presente, ainda que de forma implícita, em todos os textos, e remonta ao estreitamento dos laços entre leitor, conhecimento e autor. Sarmento et al. (2010) ressaltam que a utilização do pronome de tratamento você rompe a barreira entre cientista e leitor, e diminui a impessoalidade presente nos textos científicos. Abaixo, além do destaque à utilização desse recurso nos textos analisados, também pode ser observada uma sugestão de atividade para o leitor pelo emprego do modo imperativo: Pesquise!

Há muito mais informações curiosas a respeito dos cogumelos. Pesquise! Tenho certeza de que é você quem vai se derreter pelo prazer de aprender. [Texto F]

E se você está se perguntando o que a vacina tem a ver com tudo isso, saiba que ela potencializa a ação do nosso sistema imunológico. [Texto H] 
Observamos, ainda, que, ao final de alguns dos textos, geralmente são retomados os conhecimentos anteriormente expostos, e feitas sugestões e perguntas. Conforme destacado no texto I:

Basta um pouco de sabonete comum e água para limparmos a pele e mantermos as bactérias que nos protegem no número certo. E aí, está precisando de uma chuveirada?!

Portanto, a estratégia parece ser a de colocar o leitor como partícipe na situação evocada pelo texto, levando-o a posicionar-se ou agir em relação ao conteúdo ali abordado.

\section{Presença de narrativas}

Segundo Ribeiro e Martins (2007, p. 294), “A literatura mais recente sobre currículos vem apontando uma tendência de se incluir e valorizar o uso de narrativas como recurso didático em sala de aula, não apenas nas aulas de línguas." Ao constatar a presença de narrativas em textos de divulgação científica, Zamboni (2001) as considera como "recursos argumentativos" que ilustram o tema atraindo o leitor e mantendo o seu interesse.

A presença de narrativas foi observada em apenas três textos, sendo que nenhum deles apresentou uma estrutura narrativa por completo. O que se observou foi a presença de pequenas narrativas, logo no início dos artigos, as quais colocavam o leitor na cena principal da história. Abaixo, estão representados dois dos trechos referidos:

O dia está quente e, de repente, cai aquela chuva para refrescar. Bastam as primeiras gotas tocarem o solo para sentirmos aquele agradável cheirinho de terra molhada. Um cientista diria: "Huumm, como é bom esse cheirinho de... Bactérias!” É isso aí! O aroma que sentimos vem desses seres microscópicos [...] [Texto E]

Bate a fome e você invade a cozinha à procura de algo para comer. Depois de inspecionar a geladeira de cima a baixo sem encontrar nada que desperte a atenção do seu estômago, você se lembra daquele delicioso pãozinho bem guardado no forno. Abre o pacote com a boca cheia d'água e - argh! - o que é essa coisa verde?! [Texto G]

As narrativas são similares, partem de cenários familiares e ações cotidianas - um dia quente que é seguido por chuva, uma "visita" à geladeira em busca de alimento, e a descoberta de produtos com a validade vencida - para atrair o leitor aos temas científicos a serem abordados: relação ecológica envolvendo as bactérias (Texto E), os microrganismos que degradam alimentos e outros produtos (Textos G e K).

Sobre o pequeno número de narrativas observado e, até mesmo, sobre a ausência de um texto elaborado totalmente nesse gênero nas seções analisadas, devemos ressaltar que a revista possui outras seções nas quais a narrativa ganha o foco principal, como a seção Contos e Lendas. Mesmo assim, as narrativas poderiam ser mais exploradas nas seções em tela, uma vez que elas envolvem e provocam emoções mais do que a transmissão de informações (TOROK, 2008). 


\section{Presença de analogias}

Para as finalidades desta pesquisa, consideramos analogia uma comparação entre dois conceitos/fenômenos/assuntos/objetos, os quais possibilitam estabelecer uma relação - seja de semelhança, seja de diferença - entre si.

$\mathrm{Na}$ DC, os leitores são constantemente colocados em contato com termos novos, oriundos do discurso científico, os quais podem não ter os significados plenamente compreendidos, uma vez que esse discurso não lhes é familiar. A analogia contribui na apresentação de um conceito novo, pois, a partir de algo familiar (o análogo), é possível aproximar-se de um conhecimento novo (o alvo). Sobre esta discussão, Santos, Terán e Silva-Forsberg (2011) ressaltam que o pensamento analógico aproxima conteúdos de campos de saber diferentes, o que favorece a conexão entre conhecimentos prévios do leitor e o que lhe é apresentado como novidade.

Todavia, é preciso cautela no que diz respeito às relações que se pretende fazer ao usar analogias. Proposições erradas ou complexas demais podem ter o resultado inverso ao esperado. Silva, Pimentel e Terrazzan (2011, p. 166) citam as orientações obtidas a partir das pesquisas pioneiras de Curtis e Reigeluth ${ }^{5}$ sobre o uso de analogias: "Em casos em que o análogo não é familiar para os alunos, seria melhor explicar ou descrever o análogo. Se o análogo é familiar, mas complexo, seria mais benéfico revisá-lo antes de usar a analogia”.

Apesar da relevância do uso de analogias na educação científica, apenas três dos 12 textos analisados lançaram mão desse recurso. Abaixo, estão destacados alguns dos trechos nos quais as analogias aparecem: (análogo):

No texto $C$, os autores fazem uma analogia entre as macrófitas (alvo) e o capim

Ali encontram-se as macrófitas aquáticas, plantas que se parecem com o capim terrestre $[. .$.

Já no texto F, é feita uma analogia entre o termo esporos - que representa o alvo - e a semente, análogo que os autores supõem ser mais familiar para os leitores:

Essas células são chamadas de esporos e possuem a mesma função que a semente de uma planta: dar origem a um novo organismo.

No texto I, temos um bom exemplo de como uma analogia pode auxiliar a compreensão. O alvo é um termo científico distante do vocabulário infantil (epiderme), e o análogo escolhido para a relação é de conhecimento de todos e bastante familiar (o tecido de nossas roupas).

Na pele existem as células que formam a epiderme (a camada mais externa da pele, essa que tocamos), que é como um tecido mesmo, como o de nossas roupas.

\footnotetext{
${ }^{5}$ CURTIS, R. V.; REIGELUTH, C. M. The use of analogies in written text. Instructional Science, New York, v. 13, n. 2 , p. 99-117, 1984.
} 
A observação de poucos trechos que fazem uso de analogias, nas seções analisadas, vai ao encontro dos resultados obtidos por Silva, Pimentel e Terrazzan (2011), que analisaram a presença de analogias na revista como um todo, encontrando somente 88 analogias em 1.022 textos. Considerando-se a contribuição das analogias para a representação de conceitos e a força das imagens e ideias assim constituídas, esperava-se encontrá-las em maior número nas seções da revista que foram objeto deste estudo.

\section{Contextualização dos conhecimentos científicos}

A contextualização pode ter diferentes significados e ocorrer por meio de referências à realidade dos estudantes, abarcando desde as experiências do cotidiano, as aplicações ao trabalho até o exercício da cidadania, em um dado contexto sociocultural, produzido historicamente. $\mathrm{Na}$ DC, a contextualização aproxima o cidadão de conceitos da sociedade tecnológica, de modo a compreendê-la criticamente e a refletir sobre esses conhecimentos em suas vivências diárias.

Com respeito aos textos examinados, além de fazerem referência a fenômenos do dia a dia, alguns declaram, logo de início, a sua intenção de explicar situações cotidianas a partir de uma perspectiva científica, explicitando essa proposta no próprio título. Por exemplo, no artigo Por que temos que tomar banho? (texto I), que descreve a interação entre os microrganismos e os humanos, a higiene pessoal é utilizada como fio condutor:

Logo, tomar banho não é só para ficar cheiroso. Mas se você estiver cheirando mal, significa que muitas bactérias e restos de pele se acumularam. A saída é procurar o chuveiro mais próximo.

O texto J, Por que o bolo cresce no forno?, discorre sobre o processo de fermentação e explica por que é possível enxergar pequenos orifícios na massa, mencionando alimentos familiares:

O gás carbônico expande a massa, tornando-a macia e com os buraquinhos que vemos nos pães, nas pizzas e nos bolos depois de prontos.

No Texto B, Por que algumas bactérias são aliadas da saúde?, são apresentados alguns dos organismos presentes na flora intestinal humana, relacionando-os com a tecnologia de produção industrializada de alimentos, empregada em produtos tipicamente consumidos pelas crianças, como os iogurtes.

Em muitos países, bactérias benéficas são adicionadas a chocolates, sorvetes, barras de cereais, margarinas e maioneses. No Brasil, elas são encontradas, principalmente, em bebidas lácteas e iogurtes.

Lopes (1999, p. 218) analisa as implicações do uso dos saberes cotidianos na compreensão do conhecimento científico, e afirma: "O conhecimento científico é difícil, justamente, porque rompe com as concepções do conhecimento cotidiano. Mas sua dificuldade não é intransponível, uma vez que é essencialmente uma produção humana”. 
No que diz respeito ao confronto com o senso comum, a maioria dos textos situa os microrganismos em processos diversos, indo de encontro ao pensamento, amplamente difundido na população, de que microrganismos (como bactérias e fungos) estão sempre associados a situações de adoecimento. Embora alguns artigos abordem questões de saúde/doença, percebe-se a preocupação em não apresentar os microrganismos apenas como maléficos para as pessoas, como visto no trecho abaixo:

Uma coisa que nem todo mundo sabe é que sobre a nossa pele e mucosas - mucosa é a pele fininha e úmida, como a da boca e a do interior do nariz - existem bactérias chamadas comensais, isto é, bactérias que convivem conosco sem necessariamente causarem doenças. [Texto I].

Considerando que a maior parte dos microrganismos não causam doenças, esse enfoque é de suma importância, e essa informação deve estar presente em qualquer texto que pretenda informar jovens leitores sobre microbiologia (EMMERT, 2008).

\section{Possibilidades no Ensino de Ciências e Biologia}

Tendo em vista que os textos de DC podem ser empregados no Ensino, identificam-se algumas possibilidades de utilização como material de apoio em aulas de ciências. Conforme Rocha (2012), na opinião de professores do Ensino Fundamental, por ele entrevistados, os TDC: possibilitam a contextualização dos conteúdos escolares, propiciam os debates e as interações, favorecem o desenvolvimento de argumentos e de posicionamentos críticos e incentivam a busca de mais informações em outras fontes. Abaixo, estão destacados trechos que apresentam conceitos científicos na intersecção entre saberes escolares e problemas do dia a dia.

Fazendo uso dos microrganismos, os agricultores fertilizam o solo de maneira natural e ajudam a aumentar a produtividade agrícola sem transtornos ao ambiente. [Texto A].

É bem provável que você tenha ouvido por aí: "A Amazônia é o pulmão do mundo.” Bobagem! Embora as florestas tenham, sim, grande importância na produção de oxigênio, como é o caso da Floresta Amazônica, o grande pulmão do mundo, para usar a mesma expressão, está nas águas - ou melhor, nos seres que habitam rios e mares [...]. No que diz respeito à produção de oxigênio, portanto, é extremamente importante preservar os ambientes aquáticos! [Texto C].

A grande vantagem do plástico biodegradável é reduzir a poluição do meio ambiente. [Texto D].

O texto A aborda a microbiologia com enfoque ecológico, explicando a importância das bactérias fixadoras de nitrogênio para as plantas. Ele permite discutir o impacto da agricultura no ambiente e as alternativas ao uso de fertilizantes químicos. Já o texto C lança uma nova perspec- 
tiva sobre a importância dos rios e mares na produção de oxigênio, e possibilita a reflexão sobre questões socioambientais. O texto $\mathrm{D}$, por sua vez, enfoca a microbiologia industrial e explica a produção de plástico a partir de uma fonte renovável, permitindo examinar a influência do desenvolvimento tecnológico na preservação do ambiente. Como já discutido, alguns conceitos e processos científicos, para serem entendidos pelos alunos, requerem a mediação do professor.

Almeida e Giordan (2014) investigaram como crianças de quarto ano do Ensino Fundamental (EF) falam a respeito de suas leituras de artigos da revista $\mathrm{CHC}$, e concluíram que elas compreendem as ideias, as reconstroem e retificam, articulando elementos da linguagem científica ao seu discurso cotidiano. Observaram, também, que, nas interações sociais, a partir do TDC, compartilham aprendizados, construindo cooperativamente significados para a leitura. De modo semelhante, o estudo fenomenológico de Burakgazi e Yildirim (2014), examinando DC e as impressões e experiências de crianças turcas de dez a 12 anos, do quarto e quinto ano do EF, mostra que, para elas, as revistas de DC, como a Science and Child, permitem aprender tópicos interessantes de maneira complementar ao conhecimento escolar, e que essas informações são confiáveis e apresentadas em um estilo apropriado a sua faixa etária, despertando a curiosidade e permitindo aprender e reter conhecimento atualizado de um modo gratificante.

\section{Considerações finais}

A partir do estudo de textos de DC direcionados ao público infantil, foi possível estabelecer relações com a análise desenvolvida por Zamboni (2001), sobre os textos voltados para o público adulto. Resguardadas as diferenças referentes às audiências a que se destinam os textos analisados e os do trabalho dessa autora, foi possível observar a presença significativa de elementos similares aos descritos por ela na estrutura dos textos examinados. Este resultado corrobora a ideia de que a divulgação científica apresenta um discurso próprio, que visa aproximar a ciência dos leitores, sejam eles adultos, sejam eles crianças.

Tomando os textos da revista Ciência Hoje das Crianças como material empírico, foi possível observar que esses documentos exploram uma característica marcante das crianças: a curiosidade. Nas seções Você sabia e Por que, o apelo inicial à leitura está centrado na abordagem de temas científicos em interface com o cotidiano, o que, por vezes, é explicitado no próprio título. São empregadas frases de impacto que produzem imagens familiares, em textos curtos, mas que abordam os temas de forma inteligente, sem parecer subestimar o público infantil. Nota-se que o uso de imagens é profundamente explorado na revista, porém, nessas seções, sua utilização em forma de esquemas ou desenhos técnicos, a fim de auxiliar na explicação do texto escrito, é pouco frequente. Os desenhos que compõem os textos parecem dar uma identidade às seções, e estão mais relacionados ao apelo inicial à leitura. As ilustrações marcam o endereçamento ao público infantil. E esse público, predisposto a novidades, não exige receber as notícias científicas mais recentes, porque está descobrindo o mundo, mas precisa surpreender-se pela forma da abordagem.

A análise aponta uma preocupação dos autores em recuperar conhecimentos, que costumam ser tácitos em publicações dirigidas à comunidade científica, e, também, no emprego de pausas, a fim de explicar conceitos e termos básicos das ciências. Aqui, se pode notar a construção do discurso de divulgação científica, na interface entre os saberes do enunciador e as 
representações que ele faz do seu leitor, sendo frequente a presença de elementos que promovem a interlocução direta com o público, sobretudo a partir do uso do pronome de tratamento você, com a pretensão de aproximá-lo e incluí-lo no discurso materializado no texto.

No que diz respeito à contextualização do conhecimento científico, ela é realizada mediante a proposição de questões envolvendo situações cotidianas a serem respondidas a partir de abordagens atualizadas e interdisciplinares acerca da microbiologia. Os enfoques são variados, incluindo diferentes áreas, tais como: ecologia, indústria, ambiente, tecnologia e saúde. Sendo assim, a popularização do conhecimento visa ampliar os saberes no que se refere à presença dos microrganismos no dia a dia, confrontando a visão de senso comum que os associa somente às doenças. $\mathrm{O}$ material analisado, devido a essas características, possibilita, ainda, uma série de discussões a serem realizadas por professores e alunos em aulas de ciências.

Portanto, conclui-se que a divulgação científica ganha espaço como um campo de conhecimento importante para aproximar ciência e público, enfatizando as implicações de atividades científicas na vida das pessoas. Desse modo, se faz necessário mostrar que a prática científica, como uma atividade humana, está sujeita a interesses, sucessos e fracassos, produzindo o desenvolvimento do conhecimento em um contexto social e histórico. A desconstrução de um imaginário idealizado de ciência, aproximando essa prática da sociedade, é compromisso fundamental da atividade de divulgação científica, seja direcionada para adultos, seja para crianças.

\section{Referências}

ABREU, E. O. Você sabia que existem bactérias que produzem plástico? Ciência Hoje das Crianças, Rio de Janeiro, n. 207, p. 17, nov. 2009.

AIRES, J. A. et al. Divulgação científica na sala de aula: um estudo sobre a contribuição da revista Ciência Hoje das Crianças. In: ENCONTRO NACIONAL DE PESQUISA EM EDUCAÇÃO EM CIÊNCIAS, 4., 2003, Bauru. Atas... Bauru: ABRAPEC, 2003. 1 CDROM.

ALMEIDA, S. A.; GIORDAN, M. A revista Ciência Hoje das Crianças no letramento escolar: a retextualização de artigos de divulgação científica. Educação e Pesquisa, São Paulo, v. 40, n. 4, 2014. Disponível em: <http://www.scielo.br/pdf/ep/2014nahead/ aop1219.pdf>. Acesso em: 12 jun. 2014.

ASTOLFI, J.; DEVELAY, M. A didática das ciências. 2. ed. Campinas: Papirus, 1991.

BAREDES, C. Um livro de ciência para crianças é um livrinho de ciência? In: MASSARANI, L. (Ed.). Ciência e criança: a divulgação científica para o público infanto-juvenil. Rio de Janeiro: Museu da Vida, 2008. p. 8-13.

BONOMO, A.; CUNHA, J. M. Por que temos de tomar banho? Ciência Hoje das Crianças, Rio de Janeiro, n. 176, p. 20, jan./fev. 2007. 
BRAGA, S. A. M.; MORTIMER, E. F. Os gêneros de discurso do texto de biologia dos livros didáticos de ciências. Revista Brasileira de Pesquisa em Educação em Ciências, São Paulo, v. 3, n. 3, p. 56-74, 2003. Disponível em: <http://revistas.if.usp.br/rbpec/article/ viewArticle/150>. Acesso em: 13 jun. 2014.

BURAKGAZI, S. G.; YILDIRIM A. Accessing science through media: uses and gratifications among fourth and fifth graders for science learning. Science Communication, Thousand Oaks, v. 36, n. 2, p. 168-193, 2014. Disponível em: <http://scx.sagepub.com/ content/36/2/168>. Acesso em: 16 jun. 2014.

CANDOTTI, E. Ciência na educação popular. In: MASSARANI, L.; MOREIRA, I. C.; BRITO, F. (Org.). Ciência e público: caminhos da divulgação científica no Brasil. Rio de Janeiro: UFRJ, 2002. p. 15-23. (Terra incógnita).

CAPOZOLI, U. A divulgação e o pulo do gato. In: MASSARANI, L.; MOREIRA, I. C; BRITO, F. (Org.). Ciência e público: caminhos da divulgação científica no Brasil. Rio de Janeiro: UFRJ, 2002. p. 121-131. (Terra incógnita).

COSTA, K. F. S.; MEDEIROS, L. C. Por que algumas bactérias são aliadas da saúde?

Ciência Hoje das Crianças, Rio de Janeiro, n. 217, p. 12, out. 2010.

EMMERT, E. Microbiology for children: what are they learning? BioScience, Washington, v. 58, n. 9, p. 890-891, 2008. Disponível em: < http://bioscience.oxfordjournals.org/ content/58/9/890.full>. Acesso em: 12 jun. 2014.

FREIRE, A. C. C. M.; MASSARANI, L. A cobertura de ciência para crianças: um estudo de caso em dois jornais brasileiros. Alexandria: Revista de Educação em Ciência e Tecnologia, Florianópolis, v. 5, n. 3, p. 101-126, 2012. Disponível em: < http://alexandria.ppgect.ufsc.br/ files/2012/11/AnaCatarina.pdf $>$. Acesso em: 14 jun. 2014

GERMANO, M. G.; KULESZA, W. A. Popularização da ciência: uma revisão conceitual. Caderno Brasileiro de Ensino de Física, Florianópolis, v. 24, n. 1, p. 7-25, abr. 2007.

GUIMARÃES, J. P.; BORGES, R. G. Por que devemos vacinar os animais? Ciência Hoje das Crianças, Rio de Janeiro, n. 186, p. 20, dez. 2007.

LIMA, M. E. C. C. Por que alimentos, cosméticos e medicamentos estragam? Ciência Hoje das Crianças, Rio de Janeiro, n. 225, p. 17, jul. 2011.

LOPES, A. R. C. Conhecimento escolar: ciência e cotidiano. Rio de Janeiro: EDUERJ, 1999.

MACHADO, A. Os dois lados de Angelo Machado. In: MASSARANI, L.; MOREIRA, I. C.; BRITO, F. (Org.). Ciência e público: caminhos da divulgação científica no Brasil. Rio de Janeiro: UFRJ, 2002. p. 143-153. (Terra incógnita).

MARTINS, I.; GOUVÊA, G.; PICCININI, C. Aprendendo com imagens. Ciência e

Cultura, Campinas, v. 57, n. 4, p. 38-40, dez. 2005.

MICHELETTI NETO, J. C. Por que os alimentos mofam? Ciência Hoje das Crianças, Rio de Janeiro, n. 195, p. 12, out. 2008. 
NASCIMENTO, T. G.; REZENDE JUNIOR, M. F. A produção de textos de divulgação científica na formação inicial de licenciandos em ciências naturais. Revista Brasileira de Pesquisa em Educação em Ciências, São Paulo, v. 10, n. 1, 2010. Disponível em: <http://revistas.if.usp.br/rbpec/article/view/13/12>. Acesso em: 11 mar. 2014.

PEREIRA, L. T. Você sabia que alguns cogumelos se reproduzem de maneira parecida com as plantas? Ciência Hoje das Crianças, Rio de Janeiro, n. 198, p. 11, jan./ fev. 2009.

QUEIROZ, S. L.; FERREIRA, L. N. A. Traços de cientificidade, didaticidade e laicidade em artigos da revista "Ciência Hoje" relacionados à química. Ciência \& Educação, Bauru, v. 19, n. 4, p. 947-969, 2013.

QUESADO, L. B. Você sabia que a Floresta Amazônica não é responsável por grande parte do oxigênio que respiramos? Ciência Hoje das Crianças, Rio de Janeiro, n. 209, p. 20, jan./fev. 2010.

REIS, J. Ponto de vista: José Reis. In: MASSARANI, L.; MOREIRA, I. C.; BRITO, F. (Org.). Ciência e público: caminhos da divulgação científica no Brasil. Rio de Janeiro: UFRJ, 2002. p. 73-77. (Terra incógnita).

RIBEIRO, R. M. L.; MARTINS, I. O potencial das narrativas: uma análise em livros didáticos de física. Ciência \& Educação, Bauru, v. 13, n. 3, p. 293-309, 2007.

ROCHA, M. B. O potencial didático dos textos de divulgação científica segundo professores de ciências. Revista Brasileira de Ensino de Ciência e Tecnologia, Ponta Grossa, v. 5, n. 2, p. 47-68, 2012. Disponível em: < http://revistas.utfpr.edu.br/pg/index.php/rbect/ article/view/1263>. Acesso em: 13 jun. 2014.

ROEHE, P. M. Por que alguns vírus são mutantes? Ciência Hoje das Crianças, Rio de Janeiro, n. 246, p. 12, jun. 2013.

SANTOS, S. C. S.; TERÁN, A. F.; SILVA-FORSBERG, M. C. Analogias em livros didáticos de biologia no ensino de zoologia. Investigações em Ensino de Ciências, Porto Alegre, v. 15 , n. 3 , p. $591-603,2011$.

SARMENTO, A. C. et al. Divulgação científica para o público infantil: análise da revista Ciência Hoje das Crianças - impressa. Diálogos \& Ciência, Feira de Santana, n. 12, p. 25-38, mar. 2010.

SILVA, A. M. P. Você sabia que cheirinho de terra molhada é obra de bactérias? Ciência Hoje das Crianças, Rio de Janeiro, n. 202, p. 7, jun. 2009.

SILVA, J. T. Por que o bolo cresce no forno? Ciência Hoje das Crianças, Rio de Janeiro, n. 175 , p. 17 , dez. 2006.

SILVA, L. L.; PIMENTEL, N. L.; TERRAZZAN, E. As analogias na revista de divulgação científica Ciência Hoje das Crianças. Ciência \& Educação, Bauru, v. 17, n. 1, p. 163-181, 2011. 
SILVEIRA, C. L. A visão antropocêntrica em uma revista de divulgação científica para crianças. 2013. 85 f. Trabalho de Conclusão de Curso (Licenciatura em Ciências Biológicas) - Universidade Federal do Rio Grande do Sul, Porto Alegre, 2013.

SIQUEIRA, S. C.; MACRAE, A. Por que microrganismos são importantes para as plantas? Ciência Hoje das Crianças, Rio de Janeiro, n. 221, p. 12, mar. 2011.

STUDART, D. C. Conhecendo a experiência museal das crianças por meio de desenhos. In: MASSARANI, L. (Ed.). Ciência e criança: a divulgação científica para o público infanto-juvenil. Rio de Janeiro: Museu da Vida, 2008. p. 20-31.

TOROK, S. Falar de ciência para crianças: algumas dicas. In: MASSARANI, L. (Ed.).

Ciência e criança: a divulgação científica para o público infanto-juvenil. Rio de Janeiro: Museu da Vida, 2008. p. 20-31.

ZAMBONI, L. M. S. Cientistas, jornalistas e a divulgação científica: subjetividade e heterogeneidade no discurso da divulgação científica. Campinas: Autores Associados, 2001.

Artigo recebido em 06/09/13. Aceito em 20/06/14. 